\title{
FLIGHT CREW FATIGUE AND THE EFFECT ON AIRLINE BUSINESS
}

\author{
MOHD RIZAL PALIL* \\ LOKHMAN HAKIM OSMAN \\ MARA RIDHUAN CHE ABDUL RAHMAN \\ MOHD HELMI ALI \\ EZAD AZRAI JAMSARI \\ MAHATHIR AHMAD \\ NURUL AISHAH BINTI KHAIRUDDIN \\ NUR AAINA AQILAH BINTI JAMALUDDIN \\ Faculty of Economics and Management, Universiti Kebangsaan Malaysia, 43600 Bangi, Selangor, Malaysia. \\ ${ }^{*}$ Corresponding author Email: mr palil@ukm.edu.my \\ IBNOR AZLI IBRAHIM \\ Universiti Islam Sultan Sharif Ali, Brunei Darussalam \\ IDA SURIYA ISMAIL \\ Faculty of Accountancy,Universiti Teknologi MARA Shah Alam \\ 40450 Shah Alam, Selangor, Malaysia
}

\begin{abstract}
The paper discusses previous studies on the effect of fatigue among flight crews and their effect on airline businesses. Fatigue is a major concern in flight operations as many reports were issued on this problem among flight crew. The long flight duration requires them to travel several time zones, which leads to fatigue. Furthermore, the change of time zones could also lead to the occurrence of jet lag and subsequently causes fatigue too. Fatigue can occur during and after the travelling period, and it takes a while to recover from it. This study aims to observe the effects of fatigue experienced by flight crew. The results show that fatigue causes many health problems such as an increase in cancer risk, depression, mental illness and miscarriage. Additionally, fatigue reduces one's work productivity as working in a tired state reduces work performance. Furthermore, fatigue also leads to other problems such as anger, anxiety, stress and job dissatisfaction. With the studies conducted on the issue of fatigue, airlines should take appropriate actions to minimise or solve the problem to ensure that fatigue problem will not affect flight crew performance and the airline business.
\end{abstract}

Keywords: Fatigue, health, work productivity, flight crew, time zone, airline business

\section{INTRODUCTION}

Long flights, especially flights that traverse multiple time zones will cause many health problems such as fatigue. Fatigue is defined as extreme tiredness and stress, often associated with poor sleep conditions, selfinduced sleep disorders and stress during flight. Mustopo (2011) conducted a study on Flight
Safety and Fatigue Psychological Aspects and discovered that there are two types of fatigue. The first type is the short-term fatigue. It is usually associated with a lack of sleep or rest, excessive physical or mental work, long hours of work, and jet lag. The second type is the longterm fatigue or known as chronic fatigue. This type of fatigue stemmed from a number of causes such as stress, employment or 
household issues, financial problems and workload. Given that fatigue occurs frequently among aviation crew such as flight attendants and pilots, this study will explore how far does the fatigue affect their jobs performance. Therefore this paper discusses previous studies on the effect of fatigue among flight crews and their effect on airline businesses. Several past studies have been analysed and discusses in the paper.

\section{FATIGUES AMONG FLIGHT CREWS AND THEIR EFFECT ON PERFOMANCE}

Ariznavarreta, Cardinali, Villanua, Granados, Martin, Chiesa and Tresguerres (2002) conducted a study on circadian rhythms in airline pilots submitted to long-haul trans meridian flights. The study found that their resting heart rate is low. The temperature rhythm shows a rigid reaction after the light/dark cycle, which is closely related to the biological clock. Psychometric assessments show that desynchronisation affects all pilots. Other results show age-related variations, with more effects on young pilots. There is no consistent effect found on the directions of the flights.

Rafnsson, Hrafnkelsson and Tulinius (2000) on the other hand conducted a study on the incidence of cancer among commercial airline pilots. The objective of this study is to illustrate the pattern of cancer in the cohort of commercial pilots via a follow-up with the Iceland Cancer Enrolment. This is a retrospective cohort study involving 458 pilots with an emphasis on the sub-cohort work for an airline operating on international routes. Cohort computerised files are the records associated with the Enrolment based on a personal identification number. The expectations on the number of cancer cases are calculated based on the number of person-years at specific sites for men, as provided by the Enrolment. The number of separate analyses is made according to several different exposure variables. The results showed a high incidence of "malignant melanoma" among pilots.

Cabons, Deharvengt, Grau, Maille, Berechet, and Mollard (2012) researched and established the guidelines to implement the Fatigue Risk Management Systems for the French regional airlines. This study discusses the relevant research aimed at providing the overall scientific basis for the implementation of the Fatigue Risk Management System (FRMS). The latest research evaluated the use of different tools and indicators, which are then integrated into the FRMS. The results showed a significant reduction in sleep rate of up to $40 \%$ from the normal sleep requirement of aircrew, resulting in an increased fatigue during flight.

In addition, Ono, Watanabe, Kaneko, Matsumoto and Miyao (1991) studied the working hours and fatigue of Japanese flight attendants. There were reports of high rate of fatigue or fatigue related symptoms including back pain during flight (FA). The working hours is stressed in studying the relationship between working conditions with work stress and fatigue symptoms. From the analysis of the staff's working timetables and fatigue symptoms during international flights, it was found that there were several work-related factors that also resulted in serious FA fatigue symptoms during night and morning work, long flight times or massive time differences whereby it disrupts their biological rhythms. Based on statistical analysis, the workrelated factors include long working hours, frequents landings that often contribute to a high complaint rates of fatigue.

A study on health, sleep, and mood perceptions reported by airline crew who fly on short and long-hauls was done Haugli, Skogstad, and Hellesoy (1994). The study was conducted on the Environmental and Health Work Crew Study at the Scandinavian Airline System (SAS) in Norway in 1989. A total of 1240 respondents answered 250 questions about health, work stress, wellness, sleep problems and communication. The self-reported incidental 
health review chart focuses on the results' difference between the cockpit and cabin crew. The study also assesses the possible effects of trans meridian flights and short-haul on health taking into consideration several factors such as gender, job demand, respondents' working conditions and aircraft design. They were found to experience the same problems. More than $30 \%$ of them had dry skin problems, backache, cold, fatigue and sleep disorders. Problems reported by pilots are lower than female cabin attendants. Crew with long-haul transit routes are reported to face more health problems than those who travel short-haul. Pain, fatigue, sleep disorders and back pain are the most common issue reported by pilots. Cabin assistants' complaints are often on skin and eye problems, digestive disorders, and muscle pain. The study promotes the early discovery of transstadial transmission, which causes digestive disorders, fatigue and sleep disorders to pilots, and cabin crew of both sexes. Female cabin assistants also have the tendencies to experience menstrual disorders during their trips.

Avers, King, Thomas, Roberts, Banks and Nesthusc (2011) conducted a study titled Flight attendant fatigue: $A$ quantitative review of flight attendant comments. Their research on sleep found that all human performance is susceptible to sleep loss while daily variations in the physiological processes are associated with body clock mechanisms. The national survey of flight attendant fatigue found that long working days, consecutive working days, shortage of time, long flight delays, lack of rest and nutrition are the issues of concern. The results of the current analysis of FA's comments also support and emphasise on the same issues. From the survey, it is evident that the most significant factors of fatigue include factors related to daily work duration, lack of rest, short flight transfers, and the number of continuous working days. Most of the same issues: have been addressed and reviewed in the current study. Overall, the results of the survey and the analysis of the study found that fatigue is a major concern in flight operations.

In addition, Holcomb, Avers, Dobbins, Banks, Blackwell, and Nesthus (2009) conducted a study titled Flight attendant fatigue, part IV: Analysis of incident reports. This study examines flight attendants' reports from the Aviation Safety Reporting System (ASRS) database to identify the frequency of the fatigue reports and the crew's conditions in which fatigue occurred. In June 2008, 2,628 crew reports were downloaded from the ASRS National Aeronautics \& Space Administration (NASA) Website for reports made between January 1990 to December 2007. Civil Aerospace Medical Institute (CAMI) researchers reviewed each full form narrative and report for possible factors that may contribute to fatigue, or fatigue's indicator. The results showed that flight attendant fatigue may occur more often and require further attention. The study represents the joint efforts of international research teams of scientists and operating personnel from four different countries. Individuals, associate airlines and sponsoring agencies have partnered with NASA over the last two years to conduct extensive checks on sleep and time-consuming international flight crews.

Gander (1986) conducted a study titled International aircrew sleep and wakefulness after multiple time zone flights: A cooperative study. Based on the samples of different flight crew, NASA researchers found that the findings are straightforward and very consistent. Most crewmembers cannot sleep well during layovers $(\mathrm{L} / \mathrm{O})$. They either have their quality sleep at selected times or are lacking in quality sleep, but stay in bed longer than usual. It appears that sleep quality decreases slightly in most cases, but is further lowered after the flight to the east than the flight to the west. This reduction is reflected in the increase in MSLT in the new time zone. However, the mean of circadian sleepiness rhythm often occurs at home base after flight. Therefore, at least part of the L/O drowsiness increase may have caused a steady 
increase, which is usually exhibited at Greenwich Mean Time (GMT).

The study on spontaneous abortions among Finnish flight attendants was done by Aspholm, Lindbohm, Paakkulainen, Taskinen, Nurminen and Tiitinen (1999). They conducted a retrospective cohort study to investigate whether working as a flight attendant is associated with an increased risk of spontaneous abortion. The cabin crew data is obtained from the medical records of pregnancy. A total of 1,751 pregnancies were analysed. It was found that airline crewmembers who work during early pregnancy had a higher risk of spontaneous abortion as compared to pregnant cabin crews who work off-peak flight times. The results of this study are similar to previous studies, which show that there is an increased risk of spontaneous abortion in female cabin crews.

Caldwell (2005) on the other hand studied on fatigue in aviation. The study suggests that aviation is an important component of our transportation system, defense network and the world economy. In addition, given the technological advancements in terms of rail speed, range, load and operational efficiency, there is a little doubt that community dependence on this important asset will continue to grow. Thus, the crew will face the challenge of operating handling problematic staff and a 24-hour flight schedule. In addition, if if technology and economic factors continue to drive human beyond its capabilities, fatigue will continue to be a risk factor for the aviation field. The study on breast cancer in female flight attendants was conducted by Mawson (1998). It was found that the rate of breast cancer is higher in Finnish female flight attendants with an average of 9 to 13 years of working experience. The risk is most prominent 15 years after the adoption of female attendants in the country. This increase may be due to the lack of melatonin, a disorder associated with sleep cycle (jetlag). Chronic disorders in the circulatory system cause many health problems, as reported by shift workers. As they usually work at night and travel often between multiple time zones, they become prone to chronic disorders that are related to the circadian rhythm.

Suvanto, Partinen, Harma and IImarinen (1990) conducted a study titled Flight attendants' desynchronosis after rapid time zone changes. In this study, they measured several variables such as long sleep, quality, adaptation and recovery time on Finland's flight attendants. 285 women (aged 23-51 years) and 57 men (25-50 years old) who have experienced rapid change of time zone participated in the study. Individual factors associated with desynchronosis perceived after the time zone change are also explained. Sleep quality, perceived adjustment and recovery time depend on flight direction and in time zone over time.

A study on retaining home-base sleep hours to prevent jet lag in connection with a westward flight across nine-time zones was done by Lowden and Akerstedt (1998). The objective of this study is to test the possibility of delaying the jet lag by letting the aircrew maintain their home-base sleep-wake pattern during the layover. With the sleep-wake pattern set at the local sleep time, 19 flight attendants were scheduled to fly west, twice. In the first trip, the flight crew followed the local sleeping pattern, while on the second trip, the flight crew maintained the home sleep time. Subjects are monitored for 10 days in three particular points; before, during, and after flight. Jet lag and drowsiness are evidently reduced during the layover, but not when they are at home. It also found that jet lag seemed to be related to drowsiness and the number of awakenings during sleep. It is concluded that maintaining home-base sleep pattern reduces jet lag during the layover.

Grajewski, Whelan, Lawson, Hein, Waters, Anderson and Cassinelli (2015) studied on the miscarriage among flight attendants. This study looks at cosmic radiation and circadian disturbances as potential hazards to flight 
attendants. Flight attendants from three US carriers involving three cities were observed based on their history of pregnancy and lifestyle, medicine and job covariance. This study assesses cosmic radiation and circadian disturbances from the company's record of two million individual flights. Using the Cox regression model, the subjects were studied using two factors. The first factor is the level of flight exposure and secondly, by looking at teachers from the same city to assess whether this exposure is associated to miscarriage. The results showed that miscarriage is linked to flight hours during sleep time and high physical work demands. On the other hand, although not evident, cosmic radiation may contribute to miscarriage in flight attendants.

Another study titled Breast cancer risk among Finnish cabin attendants: A nested casecontrol study was conducted by Kojo, Pukkala, and Auvinen (2005). The study was conducted to assess the effect of work on breast cancer risk as compared to lifestyle and other factors. 1,041 cabin assistants were given self-administered questionnaires regarding their demographic, occupational and lifestyles. a total of 27 breast cancer cases were identified based on this questionnaire. The diagnosis and confirmation of breast cancer were received from Finland Cancer Registration. The exposure to cosmic radiation was estimated based on their selfreported flight history and timetable. The conditional logistic regression model was used to analyse this study. The study found that breast cancer risk in Finnish stewardesses is related to genetic factors such as family history of breast cancer. However, there is no clear evidence that these three (Demographic, occupational and lifestyles) factors are associated with breast cancer risk in Finnish pilots.

Moreover, MacDonald, Deddens, Grajewski, Whelan and Hurrell (2003) studied the job stress among female flight attendants. This study assesses the presence of chronic work pressure among flight attendants (FA) in order to examine the relationship between work pressure, psychological stress and job dissatisfaction. A total of seventy-three female FAs ( $90 \%$ of the total participants) who work in two commercial airlines completed a detailed questionnaire distributed to them. The results of this study indicate that the level of fatigue among flight attendants who work for moderate long hours is high, while anger, anxiety, depression, emphasised stress and job dissatisfaction are moderate to low or low.

\section{CONCLUSION}

In conclusion, many studies have been conducted worldwide to see how far fatigue affects the work of flight crew. Previous studies have shown that fatigue causes health problems such as cancer risk, depression, mental disorders and miscarriage. The paper also found that several important factors that caused extreme fatigue were long hours of flights, tights schedule of working hours and insufficient rest hour during flights. The study also uncover that negative impacts that suffered by crews were high incidence of "malignant melanoma" among pilots, significant reduction in sleep rate of up to $40 \%$ from the normal sleep requirement, back pain during flight, dry skin problems, backache, cold, fatigue, sleep disorders and high blood pressure. Despite having such disadvantages, the previous studies also highlighted those crews with long-haul transit routes are reported to face more health problems than those who travel short-haul. Female cabin assistants also have the tendencies to experience menstrual disorders during their trips.

Therefore, the study suggested that the airline companies need to come up with new and effective working schedule so that fatigue among crews were nor severe as the level of severity will affect passenger satisfaction and in the long run, sustainability of the airline business would be negatively affected. Conversely, crew welfare shall be emphasize more by the airline companies in line with the profit in order to have healthy environment in long haul flights in particular. Despite of the maximisation of the 
profit, continuous assessment among health of the crews need to be employed by airline companies to achieve both company's and crews' quality of life.

This study is not free from limitations, which can be addressed in future research. Future research should consider an extensive measure of crew feedback towards their working schedule. The feedback may provide input to airline companies in designing their working schedule and flights hours. . A good and effective flights schedule may yield a better view of fatigue issues. In summary, we introduced alarming negative effect on thigh working schedule toward flight attendance of, which will be useful for other potential studies in the area.

\section{Acknowledgement:}

This paper has been funded by research grant by Universiti Kebangsaan Malaysia (code: DCP2017-018/2)

\section{REFERENCES:}

Ariznavarreta, C., Cardinali, D. P., Villanua, M. A., Granados, B., Chiesa, J. J., \& Tresguerres, J. A. 2002. Circadian rhythms in airline pilots submitted to long-haul transmeridian flights. Aviation, space, and environmental medicine, 445-455.

Aspholm, R., Lindbohm, M. L., Paakkulainen, H., Taskinen, H., Nurminen, T., \& Tiitinen, A. 1999. Spontaneous abortions among Finnish flight attendants. Journal of occupational and environmental medicine, 486-491.

Avers, K. B., Nei, D., King, S. J., Thomas, S., Banks, J. O., \& Nesthus, T. E. 2011. light attendant fatigue: A quantitative review of flight attendant comments . Federal Aviation Administration Oklahoma City Ok Civil Aerospace Medical Inst.

Cabon, P., Deharvengt, S., Grau, J. Y., Maille, N., Berechet, I., \& Mollard, R. 2012. Research and guidelines for implementing Fatigue Risk Management Systems for the French regional airlines. Accident Analysis \& Prevention, 41-44.

Caldwell, J. A. 2005. Fatigue in aviation. Travel medicine and infectious disease, 85-96.

Gander, P. H. 1986. International aircrew sleep and wakefulness after multiple time zone flights: A cooperative study. Crew Factors in Flight Operations: IV. Sleep and Wakefulness in.

Grajewski, B., Whelan, E. A., Lawson, C. C., Hein, M. J., Waters, M. A., Anderson, J. L., \& Cassinelli, R. T. 2015. Miscarriage Among Flight Attendants. Epidemiology, 192.

Haugli, L., Skogstad, A., \& Hellesoy, O. H. 1994. Health, sleep, and mood perceptions reported by airline crews flying short and long hauls. Aviation, space, and environmental medicine.

Kojo, K., Pukkala, E., \& Auvinen, A. 2005. Breast cancer risk among Finnish cabin attendants: a nested case-control study. Occupational and environmental medicine, 488-493.

Lowden, A., \& Akerstedt, T. 1998. Reataining home-base sleep hours to prevent jet lag in connection with a westward flight across nine time zones. Chronobiology International, 365-376.

MacDonald, L. A., Deddens, J. A., Grajewski, B. A., Whelan, E. A., \& Hurrell, J. J. 2003. Job stress among female flight attendants. Journal of occupational and environmental medicine, 703-714.

Mawson, A. R. (1998). Breast cancer in female flight attendants. The Lancet, 626.

Mustopo, W. I. 2011. Keselamatan Penerbangan dan Aspek Psikologis "Fatigue. Jurnal Pisikobuana. Ono, Y., Watanabe, S., Kaneko, S., Matsumoto, K., \& Miyao, M. (1991). Working hours and fatigue of Japanese flight attendants . Journal of Human Ergology, 155-164. 
Rafnsson, V., Hrafnkelsson, J., \& Tulinius, H. 2000. Incidence of cancer among commercial airline pilots. Occupational and environmental medicine, 175-179.

Suvanto, S., Partinen, M., Harma, M., \& IImarinen, J. 1990. Flight attendants' desynchronosis after rapid time zone changes. Aviation, space, and environmental medicine. 
